\title{
A novel protocol of retrograde cerebral perfusion with intermittent pressure augmentation for brain protection
}

\author{
Kazuo Kitahori, MD, ${ }^{a}$ Shinichi Takamoto, MD, PhD, ${ }^{a}$ Hiroo Takayama, MD, ${ }^{a}$ Yoshihiro Suematsu, MD, PhD, \\ Minoru Ono, MD, PhD, ${ }^{a}$ Noboru Motomura, MD, PhD, ${ }^{a}$ Teturo Morota, MD, PhD, and Kengo Takeuchi, MD, PhD
}

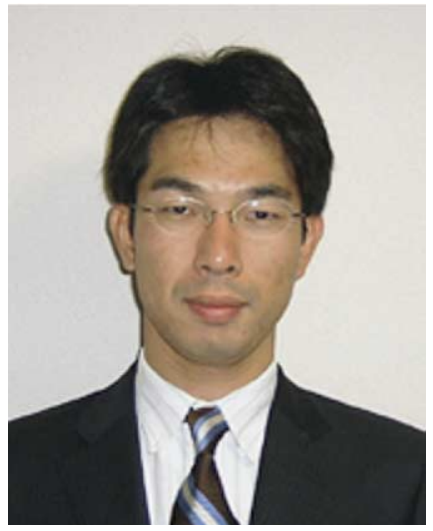

Dr Kitahori
From the Department of Cardiac Surgery ${ }^{\mathrm{a}}$ and Department of Pathology, ${ }^{\mathrm{b}}$ Graduate School of Medicine, University of Tokyo, 7-3-1 Hongo, Bunkyo-ku, Tokyo, Japan.

Received for publication June 23, 2004; revisions received Oct 24, 2004; accepted for publication Nov 2, 2004.

Address for reprints: Kazuo Kitahori, MD, Department of Cardiothoracic Surgery, Graduate School of Medicine, University of Tokyo, 7-3-1 Hongo, Bunkyo-ku, Tokyo, Japan (E-mail: KITAHORIK-SUR@h.utokyo.ac.jp).

J Thorac Cardiovasc Surg 2005;130:363-70 $0022-5223 / \$ 30.00$

Copyright $(\odot 2005$ by The American Association for Thoracic Surgery

doi:10.1016/j.jtcvs.2004.11.059
Objectives: We examined a novel protocol of retrograde cerebral perfusion with intermittent pressure augmentation to improve the clinical usefulness of this procedure, in a canine model, because a high retrograde cerebral perfusion pressure may be required to open cerebral vessels.

Methods: Eighteen dogs $(25.2 \pm 4.1 \mathrm{~kg})$ were randomly divided into the following 3 groups: circulatory arrest group (circulatory arrest alone), conventional-retrograde cerebral perfusion group (conventional retrograde cerebral perfusion at $25 \mathrm{~mm} \mathrm{Hg}$ ), and intermittent-retrograde cerebral perfusion group (retrograde cerebral perfusion at $15 \mathrm{~mm} \mathrm{Hg}$ with intermittent pressure augmentation to $45 \mathrm{~mm} \mathrm{Hg}$ ). The animals were cooled down to $26^{\circ} \mathrm{C}$ under cardiopulmonary bypass and underwent 60 minutes of circulatory arrest with or without retrograde cerebral perfusion in accordance with the protocol described. They were weaned from cardiopulmonary bypass after rewarming and observed for 12 hours after the procedures. The retinal vessels were observed as a means of noninvasive direct visualization of the cerebral vascular system. The level of Tau proteins in the cerebrospinal fluid was measured as a marker of neuronal damage.

Results: While the retinal vessels were fully distended with blood $(100 \%)$ at a retrograde cerebral perfusion pressure of $45 \mathrm{~mm} \mathrm{Hg}$ in the intermittent-retrograde cerebral perfusion group, full distension of the retinal vessels was not observed in the conventional-retrograde cerebral perfusion group (67\%). The level of Tau proteins, measured 12 hours after the operation, was lower in the intermittentretrograde cerebral perfusion group $(247 \pm 70 \mathrm{pg} / \mathrm{mL})$ than in the circulatory arrest group $(1313 \pm 463 \mathrm{pg} / \mathrm{mL} ; P<.05)$ or the conventional-retrograde cerebral perfusion group $(1449 \pm 693 \mathrm{pg} / \mathrm{mL} ; P<.05)$. Histopathologic examination revealed that the most effective brain protection was obtained in the intermittentretrograde cerebral perfusion group $(P<.05)$.

Conclusions: Intermittent-retrograde cerebral perfusion effectively opens up cerebral vessels to allow adequate blood supply to the brain, thereby minimizing brain damage. This novel method may protect the cerebral system effectively from ischemia during circulatory arrest.

$\mathrm{N}$ eurologic protection is very important during operations on the aortic arch. ${ }^{1-3}$ Circulatory arrest (CA) has been accepted and practiced at many institutions as an approach to brain protection. On the other hand, retrograde cerebral perfusion (RCP) was introduced as a perfusion adjunct to extend the safe time limit for CA. ${ }^{4,5}$ Although many theoretical advantages of RCP have been suggested, ${ }^{6-11}$ there are some reports that RCP was unable to sustain energy metabolism even in the absence of evidence of inadequate cerebral perfusion. ${ }^{12-15}$ Therefore, an optimal method to protect the brain during prolonged CA still remains to be established. 
The optimal RCP pressure has been presumed to be approximately $25 \mathrm{~mm} \mathrm{Hg}$, and an RCP pressure in excess of $25 \mathrm{~mm} \mathrm{Hg}$ has been reported to be related to an increased incidence of cerebral edema and bleeding leading to neurologic injury. ${ }^{16}$ However, other authors have used higher RCP pressures than usual and obtained good outcomes without any significant complications. ${ }^{17,18}$ In the present study, we examined RCP with intermittent pressure augmentation because we considered that a high RCP pressure of approximately 40 to $50 \mathrm{~mm} \mathrm{Hg}$ might be necessary to overcome the threshold for opening of the cerebral veins. In addition, the intermittent method was chosen to prevent cerebral edema caused by continuously high RCP pressure.

\section{Materials and Methods}

\section{Experimental Group and Protocol}

Eighteen adult mongrel dogs $(25.2 \pm 4.1 \mathrm{~kg} ; 20-32 \mathrm{~kg})$ were randomly assigned to 1 of the following 3 groups: the CA group (CA alone), the c-RCP group (conventional RCP), and the int-RCP group (RCP with intermittent pressure augmentation). The procedures conducted in the c-RCP group $(n=6)$ were the same as those in the CA group, except that RCP at a continuous pressure of $25 \mathrm{~mm} \mathrm{Hg}$ was used in addition for 60 minutes. In the int-RCP group $(n=6)$, the maxillary venous pressure controlled at $15 \mathrm{~mm} \mathrm{Hg}$ was augmented to $45 \mathrm{~mm} \mathrm{Hg}$ quickly and then decreased again to the baseline level of $15 \mathrm{~mm} \mathrm{Hg}$ as soon as it reached $45 \mathrm{~mm} \mathrm{Hg}$ every 30 seconds.

\section{Anesthesia and Hemodynamic Monitoring}

Anesthesia was induced with ketamine hydrochloride $(10 \mathrm{mg} / \mathrm{kg}$ intramuscularly) and maintained with sodium pentobarbital (Nembutal). After endotracheal intubation, the animals were maintained on positive-pressure ventilation with $100 \%$ oxygen. With the animals under adequate general anesthesia, partial laminectomy at the level of the first lumbar vertebra was performed, and a 20gauge catheter was inserted into the spinal space toward the cranial side to allow continuous pressure monitoring of the cerebrospinal fluid (CSF) and sampling at several time points: before the operation; at the end of CA; and 3, 6, and 12 hours after the operation. Then, 20-gauge catheters were positioned in the femoral artery and maxillary veins for blood sampling, and the arterial and jugular venous pressures were monitored continuously and recorded every 15 minutes. Blood samples were analyzed at the same temperature as that of the animal body for $\mathrm{pH}$, oxygen tension, carbon dioxide tension, base excess, carbonic acid, and electrolytes by using a blood gas analyzer (ABL505; Radiometer Medical; Copenhagen, Denmark). Nasopharyngeal and intraabdominal (through a minilaparotomy) temperatures were monitored.

\section{Technique and Management of Cardiopulmonary Bypass}

A median sternotomy was performed. After heparinization (300 $\mathrm{IU} / \mathrm{kg}$ ), the ascending aorta was cannulated with a $16 \mathrm{~F}$ arterial cannula, the right atrial appendage was cannulated with a $36 \mathrm{~F}$ single cannula, and cardiopulmonary bypass (CPB) was established at a flow rate of $100 \mathrm{~mL} \cdot \mathrm{kg} \cdot \min$. Membrane oxygenators (Capiox SX; Terumo Co Ltd, Tokyo, Japan) were primed with a hemodilute solution containing $800 \mathrm{~mL}$ of lactated Ringer's solu- tion, $50 \mathrm{~mL}$ of $20 \%$ human albumin, $40 \mathrm{~mL}$ of sodium bicarbonate, $200 \mathrm{~mL}$ of mannitol, and $5000 \mathrm{IU}$ of heparin. A 14-gauge catheter was inserted into the left ventricle from the apex to permit decompression of the left ventricle during the CPB. For introduction of RCP, 2 cannulas (16-gauge) were inserted into each of the maxillary veins on either side and connected to the arterial line, which were used only during RCP.

After stabilization of the body temperature and blood gases, the dog was cooled to $26^{\circ} \mathrm{C}$, while the $\mathrm{pH}$ and $\mathrm{PCO}_{2}$ were maintained by $\mathrm{pH}$-stat principles, at 7.30 to 7.50 for $\mathrm{pH}$ and 30 to $50 \mathrm{~mm} \mathrm{Hg}$ for $\mathrm{PCO}_{2}$, corrected for temperature. CPB was carried out to attain a moderate hypothermia of $26^{\circ} \mathrm{C}$ as measured by the nasopharyngeal and intraabdominal temperatures. Cardiac arrest was induced by St Thomas' Hospital solution after crossclamping of the ascending aorta. The aortic arch was incised and opened to maintain the innominate arterial pressure at the atmospheric pressure. Then the animals underwent 60 minutes of CA. During CA, brain protection procedures were carried out according to the experimental protocol as mentioned previously. After 60 minutes of CA, the aortotomy was closed and CPB was reestablished. Cardioversion was performed to resume sinus rhythm at approximately $34^{\circ} \mathrm{C}$, and mechanical ventilation was restarted. Once the temperature returned to $37^{\circ} \mathrm{C}$, the animal was slowly weaned from CPB and catecholamines were administered, if necessary, in the appropriate doses. Then, the animals were kept connected to the ventilator until they awakened.

\section{Clinical Outcomes}

All of the animals were closely monitored and evaluated in terms of the following items: eyelash reflex, voluntary respiration as a brain stem function; opening of eyes, movements of limbs as a brain cortex function; and presence and severity of convulsions as an abnormality of brain function. To explain the degree of recovery of consciousness, these items were summarized as follows: recovery of brain stem function $(0=$ no response, $1=$ positive eyelash reflex alone or voluntary respiration present, but needs ventilatory assistance, $2=$ voluntary respiration present with no need of ventilatory assistance); recovery of brain cortex function $(0=$ no response, $1=$ opening of eyes, $2=$ movements of limbs $)$; and abnormality $(0=$ serial recurrent convulsions, $1=$ temporal convulsions, $2=$ no convulsions). Numeric summing of these scores was performed to obtain a final recovery score. Lesser scores were indicative of neurologic damage.

\section{Observation of the Retinal Arteries and Veins}

Eyedrops of atropine sulfate were applied preoperatively into the eyes of the animals. A fundus camera (Genesis; KOWA Co Ltd; Nagoya, Japan) was used for taking pictures of the retina, including the retinal microvessels. For subsequent measurement of the diameter of the retinal vessels, a computer-assisted software (Photoshop v. 7.0; Adobe Systems Incorporated, San Jose, Calif) was used. The diameters of the 3 major retinal arteries and those of the veins were measured at the edge of the retinal macula and expressed as a ratio relative to the corresponding preoperative control values.

\section{Cerebrospinal Fluid}

The samples were centrifuged at 30,000 $\mathrm{g}$ for 10 minutes and stored at $-80^{\circ} \mathrm{C}$ until analysis. They were analyzed to determine the Tau 
TABLE 1. Perioperative variables

\begin{tabular}{|c|c|c|c|c|c|c|c|}
\hline Parameter & Group & Before operation & On CPB & End of cooling & End of rewarming & $\begin{array}{l}6 \mathrm{~h} \text { after } \\
\text { operation }\end{array}$ & $\begin{array}{l}12 \mathrm{~h} \text { after } \\
\text { operation }\end{array}$ \\
\hline \multirow[t]{3}{*}{$\mathrm{MAP}(\mathrm{mm} \mathrm{Hg})$} & CA & $112 \pm 8.3$ & $76.5 \pm 4.8$ & $69.3 \pm 6.8$ & $73.5 \pm 6.5$ & $91.0 \pm 8.0$ & $80.3 \pm 14.1$ \\
\hline & $\mathrm{c}-\mathrm{RCP}$ & $103 \pm 6.4$ & $56.2 \pm 2.7$ & $53.8 \pm 2.4$ & $64.2 \pm 7.4$ & $86.7 \pm 11.0$ & $71.3 \pm 16.3$ \\
\hline & int-RCP & $132 \pm 7.3$ & $85.2 \pm 3.9$ & $62.5 \pm 3.6$ & $68.2 \pm 5.4$ & $85.8 \pm 8.2$ & $65.0 \pm 7.0$ \\
\hline \multirow[t]{3}{*}{$\mathrm{Hb}(\mathrm{g} / \mathrm{dL})$} & CA & $11.1 \pm 0.6$ & $5.8 \pm 0.8$ & $5.4 \pm 0.5$ & $7.3 \pm 1.3$ & $11.4 \pm 1.3$ & $10.4 \pm 1.7$ \\
\hline & $\mathrm{c}-\mathrm{RCP}$ & $10.7 \pm 0.4$ & $6.0 \pm 1.0$ & $6.0 \pm .04$ & $7.1 \pm 0.5$ & $10.4 \pm 0.8$ & $9.2 \pm 1.2$ \\
\hline & int-RCP & $12.3 \pm 0.6$ & $6.9 \pm 0.4$ & $7.0 \pm 0.4$ & $9.3 \pm 0.3$ & $11.5 \pm 0.7$ & $10.5 \pm 0.6$ \\
\hline \multirow[t]{3}{*}{$\mathrm{PAO}_{2}(\mathrm{~mm} \mathrm{Hg})$} & CA & $330 \pm 44$ & $295 \pm 77$ & $349 \pm 56$ & $337 \pm 52$ & $213 \pm 26$ & $196 \pm 20$ \\
\hline & $\mathrm{c}-\mathrm{RCP}$ & $370 \pm 17$ & $318 \pm 29$ & $335 \pm 50$ & $321 \pm 54$ & $194 \pm 49$ & $200 \pm 48$ \\
\hline & int-RCP & $391 \pm 34$ & $325 \pm 72$ & $318 \pm 34$ & $278 \pm 72$ & $257 \pm 62$ & $187 \pm 38$ \\
\hline \multirow[t]{3}{*}{$\mathrm{PaCO}_{2}(\mathrm{~mm} \mathrm{Hg})$} & CA & $28.6 \pm 1.9$ & $31.4 \pm 2.9$ & $35.1 \pm 5.5$ & $47.0 \pm 2.8$ & $40.5 \pm 2.6$ & $45.5 \pm 5.1$ \\
\hline & $\mathrm{c}-\mathrm{RCP}$ & $27.8 \pm 3.0$ & $33.7 \pm 8.1$ & $37.1 \pm 2.4$ & $44.2 \pm 5.3$ & $32.6 \pm 3.9$ & $33.6 \pm 7.0$ \\
\hline & int-RCP & $24.7 \pm 3.3$ & $30.0 \pm 1.9$ & $37.4 \pm 1.5$ & $46.8 \pm 7.6$ & $30.6 \pm 2.2$ & $36.2 \pm 3.6$ \\
\hline \multirow[t]{3}{*}{$\mathrm{pH}$} & CA & $7.43 \pm 0.07$ & $7.43 \pm 0.08$ & $7.35 \pm 0.16$ & $7.38 \pm 0.08$ & $7.35 \pm 0.06$ & $7.41 \pm 0.23$ \\
\hline & $\mathrm{c}-\mathrm{RCP}$ & $7.47 \pm 0.12$ & $7.47 \pm 0.12$ & $7.34 \pm 0.09$ & $7.48 \pm 0.11$ & $7.42 \pm 0.09$ & $7.39 \pm 0.12$ \\
\hline & int-RCP & $7.47 \pm 0.12$ & $7.48 \pm 0.11$ & $7.32 \pm 0.10$ & $7.44 \pm 0.09$ & $7.45 \pm 0.08$ & $7.38 \pm 0.10$ \\
\hline \multirow[t]{3}{*}{ Temperature $\left({ }^{\circ} \mathrm{C}\right)$} & CA & $36.0 \pm 0.4$ & $31.6 \pm 0.7$ & $25.9 \pm 0.5$ & $36.4 \pm 0.4$ & $36.4 \pm 0.3$ & $36.8 \pm 0.5$ \\
\hline & $\mathrm{c}-\mathrm{RCP}$ & $35.2 \pm 0.5$ & $31.4 \pm 0.3$ & $26.2 \pm 0.6$ & $34.9 \pm 1.5$ & $36.7 \pm 0.2$ & $37.1 \pm 0.4$ \\
\hline & int-RCP & $35.3 \pm 0.2$ & $32.2 \pm 1.3$ & $25.5 \pm 0.7$ & $35.9 \pm 0.4$ & $36.2 \pm 0.3$ & $37.6 \pm 0.1$ \\
\hline
\end{tabular}

$M A P$, Mean arterial pressure; $H b$, hemoglobin; $P A O_{2}$, arterial partial pressure of oxygen; $P a O_{2}$, arterial partial pressure of carbon dioxide; $C A$, circulatory arrest; $c-R C P$, conventional retrograde cerebral perfusion; int- $R C P$, intermittent retrograde cerebral perfusion.

protein concentration with a commercially available kit (Fino Scholar hTAU; Eisai Co Ltd, Tokyo, Japan) based on the enzymelinked immunosorbent assay method.

\section{Pathologic Examination}

The brain was exposed by craniotomy just before each animal was fully anesthetized again for sacrifice, 12 hours after the operation, and harvested immediately after cardiac arrest was induced. The brain specimens fixed with $7 \%$ formaldehyde were sectioned, and 5 -mm block sections from the neocortex (frontal lobe and temporal lobe), hippocampus (CA1 to CA4 and molecular layer), brain stem, and medulla were embedded into paraffin wax. They were sliced into sections $5 \mu \mathrm{m}$ in thickness and stained with hematoxylin-eosin to examine infarctive or other changes. A pathologist who was blinded to the study graded the severity of injury on a scale of 0 to 5 based on the number of damaged neurons within each region: grade 0 , normal; grade 1 , less than $10 \%$; grade $2,10 \%$ to $25 \%$; grade $3,26 \%$ to $50 \%$; grade $4,51 \%$ to $75 \%$; grade 5 , greater than $75 \% .^{15}$

\section{Statistical Analysis}

Results are expressed as mean \pm SE. Analysis of variance (ANOVA) and Fisher's protected least significant difference test for multiple comparison were used for comparisons among the 3 groups. A repeated-measures ANOVA was used for comparisons of parameters between different time-points. Student $t$ test (unpaired) was used for comparisons between 2 groups. The Kruskal-Wallis test was applied for multiple comparisons of discrete variables.

All of the animals received humane care in compliance with the "Guide for the Care and Use of Laboratory Animals," published by the National Institutes of Health (NIH publication 85-23, received
1985), and with the approval of the University of Tokyo Institutional Animal Care and Use Committee.

\section{Results}

\section{Hemodynamic Data}

No significant differences were recognized among the 3 groups, as shown in Table 1. During CA, the CSF pressure

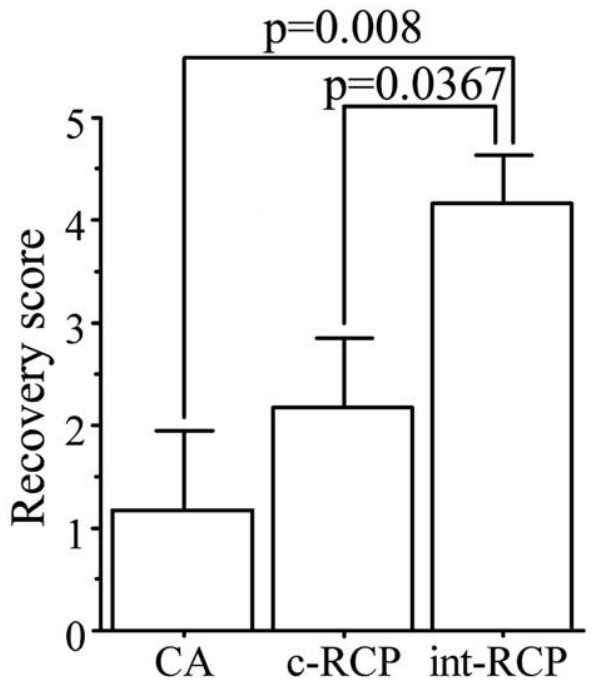

Figure 1. Comparison of the recovery scores postoperatively in each group. $C A$, Circulatory arrest; $C-R C P$, conventional retrograde cerebral perfusion; int- $R C P$, intermittent retrograde cerebral perfusion. 
was significantly lower in the CA group $\left(3.2 \pm 2.8 \mathrm{~cm} \mathrm{H}_{2} \mathrm{O}\right)$ than in the c-RCP group $\left(17.2 \pm 4.4 \mathrm{~cm} \mathrm{H}_{2} \mathrm{O}, P=.0001\right)$ and int-RCP group $\left(19.0 \pm 6.8 \mathrm{~cm} \mathrm{H}_{2} \mathrm{O}, P=.0002\right)$.

\section{Clinical Outcomes}

There were no significant differences in the total dosage per body weight of anesthetics among the 3 groups. One dog (17\%) from the CA group and 4 dogs (67\%) from the c-RCP group awakened but could not be weaned from the respirator. On the other hand, 5 dogs $(83 \%)$ from the int-RCP group awakened normally and 3 dogs $(50 \%)$ were weaned from the respirator. In the CA group, 4 dogs $(67 \%)$ had recurrent convulsions, whereas in the c-RCP group, 2 dogs (33\%) had recurrent convulsions and the remaining 2 dogs (33\%) had temporal convulsions during the rewarming period. None of the dogs $(0 \%)$ from the int-RCP group had convulsions. The mean score, shown in Figure 1, for the int-RCP group $(4.7 \pm 0.7)$ was significantly higher than that for the CA group $(1.3 \pm 0.8, P=.008)$ or the c-RCP group $(2.2 \pm 0.8, P=.0367)$.

\section{Retinal Microvessels}

In the CA group, almost no blood flow was observed in the retinal arteries and during $\mathrm{CA}$. In the c-RCP group, retrograde retinal blood flow was observed in 4 animals $(67 \%)$ at an RCP pressure of $25 \mathrm{~mm} \mathrm{Hg}$. On the other hand, no retrograde retinal blood could be detected at an RCP pressure of $25 \mathrm{~mm} \mathrm{Hg}$ in only 1 animal (17\%) of the int-RCP group, and all of the animals in this group $(100 \%)$ showed complete filling of the retinal vessels when the RCP pressure was increased to $35 \mathrm{~mm} \mathrm{Hg}$
(Figure 2). The opening pressure of the retinal vessels varied widely from 15 to $35 \mathrm{~mm} \mathrm{Hg}$ in both the c-RCP group and the int-RCP group, and the mean opening pressure was $22.2 \pm 7.2 \mathrm{~mm} \mathrm{Hg}$, with no significant difference between the 2 groups. The diameter of the retinal veins varied significantly in proportion to the RCP pressure, in the range of 15 to $45 \mathrm{~mm} \mathrm{Hg}$ (Figure 3).

\section{Tau Protein Levels in the Cerebrospinal Fluid}

The Tau protein concentration in the CSF measured 12 hours after the operation was elevated in all the groups. The concentrations were $1313 \pm 463 \mathrm{pg} / \mathrm{mL}$ in the CA group, $1449 \pm 693$ $\mathrm{pg} / \mathrm{mL}$ in the c-RCP group, and $247 \pm 70 \mathrm{pg} / \mathrm{mL}$ in the int-RCP group (Figure 4). The CSF Tau protein level was significantly lower in the int-RCP group than in the CA group $(P=.0209)$ or the c-RCP group $(P=.0435)$.

\section{Pathologic Examination Results}

The histopathologic scores for the investigated regions of the brain in each group are shown in Figure 5. The scores in the int-RCP group were significantly lower than those in the CA group in all of the regions of the brain except the medulla. Among the 3 groups, the total score for the hippocampus or all regions was the highest, reflective of the maximum brain protection, in the int-RCP group and lowest in the CA group. Neuronal degeneration was detected frequently in the CA group (Figure 6).

\section{Discussion}

Many theoretical advantages of RCP have been suggested, such as delivery of oxygen and metabolic substrates to the

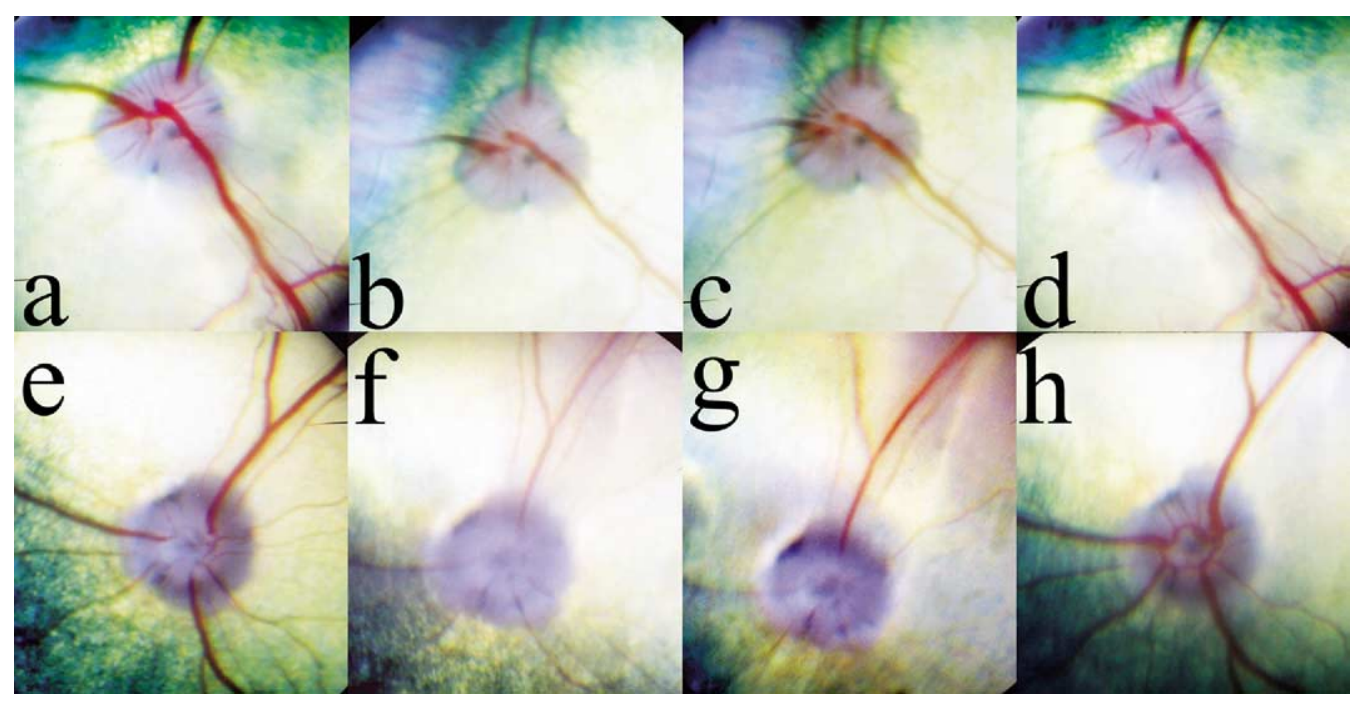

Figure 2. Retina in the intermittent retrograde cerebral perfusion (int-RCP) group. The failure of the retinal vessels to open at an RCP pressure of $25 \mathrm{~mm} \mathrm{Hg}$ (a-d). The same pressure effectively opened the retinal vessels (e-h). Before cardiopulmonary bypass (CPB) (a, e); at $15 \mathrm{~mm} \mathrm{Hg}$ of RCP (b, f); at $25 \mathrm{~mm} \mathrm{Hg} \mathrm{of} \mathrm{RCP} \mathrm{(c,} \mathrm{g);} \mathrm{at} 45 \mathrm{~mm} \mathrm{Hg} \mathrm{of}$ $\operatorname{RCP}(d, h)$. 

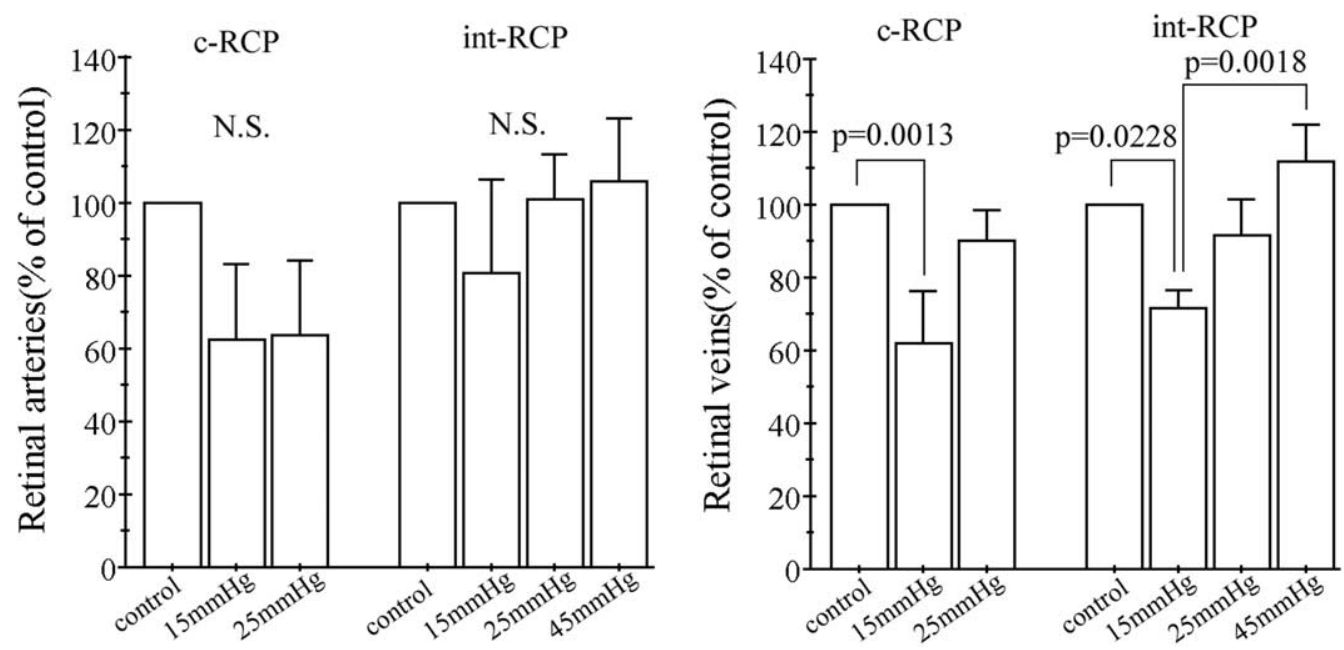

Figure 3. Values for the retinal arteries and veins are shown as a percentage of the control. The diameter of the retinal veins was smaller at an RCP pressure of $15 \mathrm{~mm} \mathrm{Hg}$ than in controls or animals in which an RCP pressure of $45 \mathrm{~mm} \mathrm{Hg}$ was used; control, before CPB; $15 \mathrm{~mm} \mathrm{Hg}, \mathrm{RCP}$ pressure of $15 \mathrm{~mm} \mathrm{Hg} ; 25 \mathrm{~mm} \mathrm{Hg}, \mathrm{RCP}$ pressure of $25 \mathrm{~mm} \mathrm{Hg} ; 45 \mathrm{~mm} \mathrm{Hg}$, RCP pressure of $45 \mathrm{~mm} \mathrm{Hg}$.

brain, removal of toxic metabolites, flushing of gaseous or atheromatous debris, homogenous cooling of the brain, and ease of establishment without the need for any additional cannulas. $^{6-11,19}$ However, some authors have questioned the validity of the neurologic protection provided by $\mathrm{RCP}^{12-15}$; therefore, an optimal method of protection of the brain during prolonged CA still remains to be established.

RCP pressure is usually controlled at a central venous pressure of less than $25 \mathrm{~mm} \mathrm{Hg}$ to avoid brain edema, ${ }^{17}$ but several clinical and experimental studies have demonstrated that RCP at a perfusion pressure of less than 25 to $30 \mathrm{~mm} \mathrm{Hg}$ provided very limited blood flow to the brain and minimal or no brain protection. ${ }^{12-15}$ The conventionally recommended RCP pressure of less than $25 \mathrm{~mm} \mathrm{Hg}$ is considered to be insufficient for opening up the cerebral microvessels and maintaining RCP, and to cause maldistribution of blood in the brain because of a sudden loss of cerebral perfusion pressure associated with conversion of antegrade to retrograde perfusion, which may cause collapse of the cortical veins and increased resistance to opening of the cerebrovenous vessels. However, much evidence has been accumulated to suggest an increased risk of perfusion-induced brain injury associated with RCP, especially when continuously high RCP pressures are used. ${ }^{16}$

Because the retina originates from the cerebral circulation embryologically, the retinal vessels have been suggested to be the only actual "window" for direct and noninvasive observation of the cerebral microcirculation. ${ }^{10,20}$ In our study, some of the retinal veins were still collapsed at an RCP pressure of $25 \mathrm{~mm} \mathrm{Hg}$ but became completely filled with blood at an RCP pressure of $45 \mathrm{~mm} \mathrm{Hg}$. Estrera and colleagues ${ }^{18}$ reported that during $\mathrm{RCP}$, the opening pressure of the middle cerebral artery was $31.8 \pm 9.7 \mathrm{~mm} \mathrm{Hg}$, and that reverse cerebral flow was identified in only $20 \%$ of those patients in whom the RCP pressure was less than $25 \mathrm{~mm} \mathrm{Hg}$. In our experiment, the opening pressure of the retinal arteries and veins was $22.2 \pm 7.2 \mathrm{~mm} \mathrm{Hg}$ (15$35 \mathrm{~mm} \mathrm{Hg}$ ) and the retinal vessels were filled in $9(67 \%)$ of

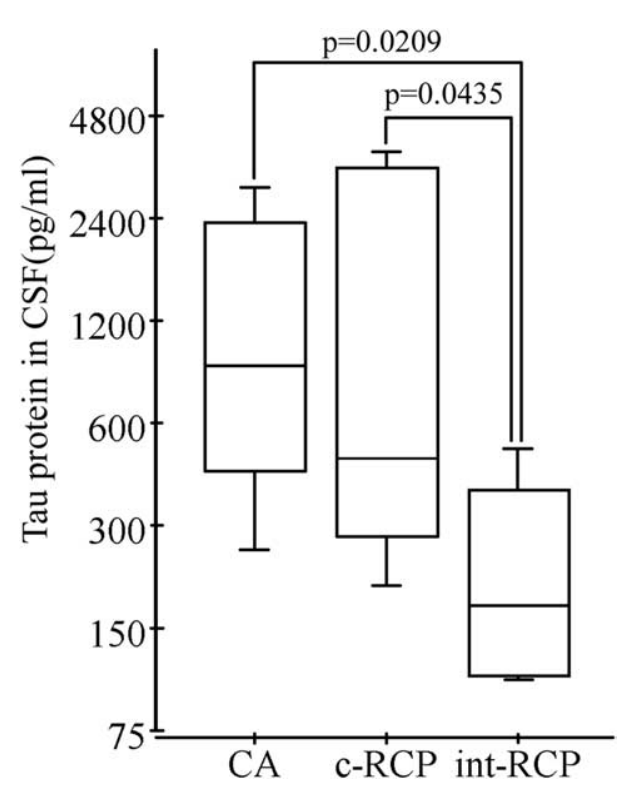

Figure 4. Concentration of Tau proteins in the CSF measured 12 hours after the operation. CSF, Cerebrospinal fluid; $C A$, circulatory arrest; $c-R C P$, conventional retrograde cerebral perfusion; int$R C P$, intermittent retrograde cerebral perfusion. 


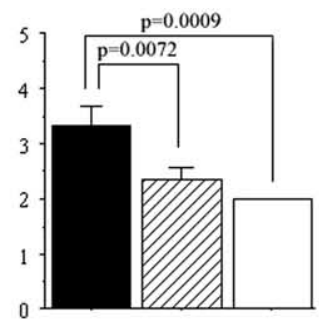

Brainstem

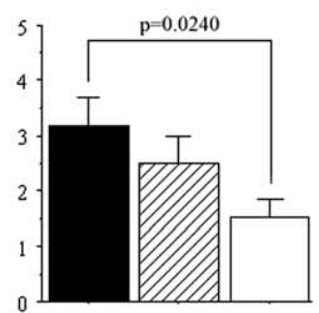

Hippocampus-CA1

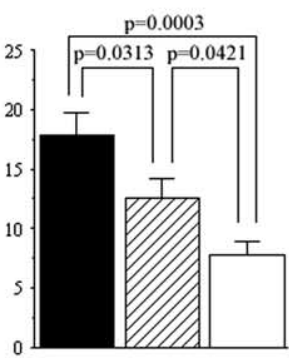

Total scores for all Hippocampus regions

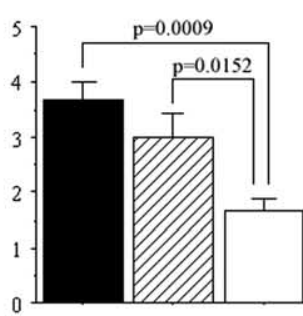

Hippocampus-CA2
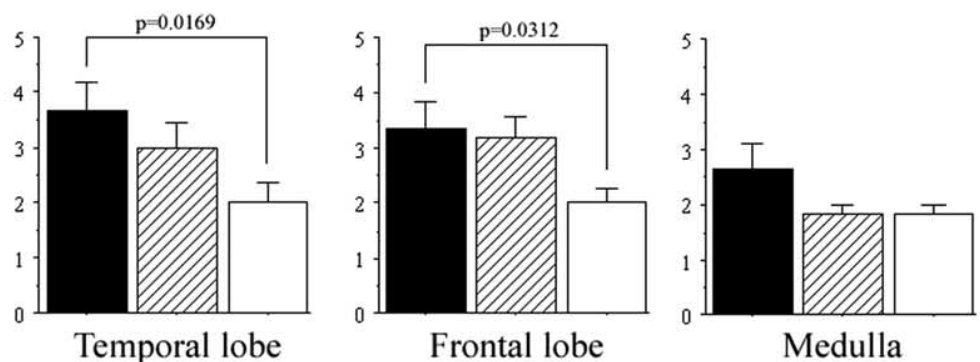

CA group

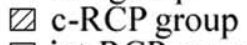

$\square$ int-RCP group

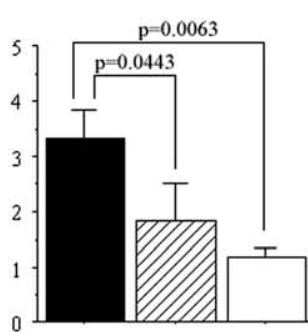

Hippocampus-CA3

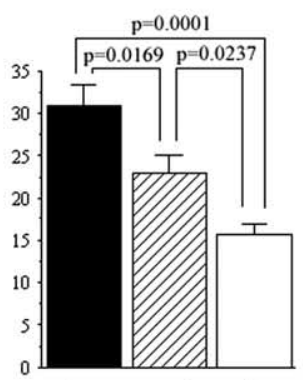

Total scores for all regions

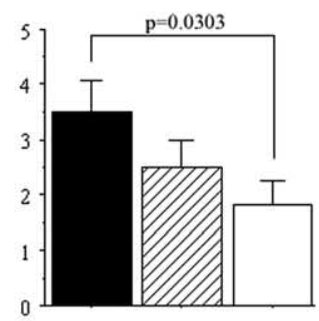

Hippocampus-CA4

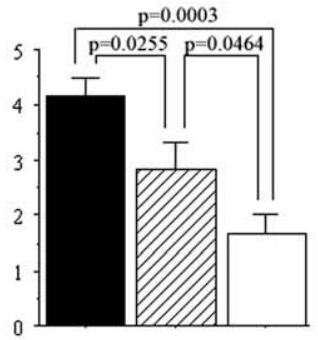

Hippocampus-

Molecular layer

Figure 5. Histopathologic scores for the investigated regions of the brain in each group. The scores of the int-RCP group were significantly better than in either of the other 2 groups, particularly in the hippocampus region.

the 12 subjects in the c-RCP and int-RCP groups at an RCP pressure of $25 \mathrm{~mm} \mathrm{Hg}$. Analysis of the time-course of changes of the CSF pressure revealed no statistically significant differences among the 3 groups. This result indicates that int-RCP might not cause brain edema more easily compared with c-RCP and CA. Therefore, we considered that the RCP pressure is a very important parameter to overcome the venous resistance of the capillaries and maintain the patency of the microvessels.

Tau proteins are microtubule-binding proteins localized in the axonal compartment of neurons. Brain injury releases the cleaved Tau proteins into the extracellular space, from where they are transported to the CSF. ${ }^{21}$ Thus, the concentration of Tau proteins in the CSF is a good marker of neuronal damage. ${ }^{22}$ Zemlan and associates ${ }^{22}$ reported that the Tau protein levels in the CSF were elevated to more than 1000 -fold in patients on the first day after brain injury compared with healthy controls. Because of the higher CSF levels of the Tau proteins in the CA group than in the int-RCP group at 12 hours after the operation in this study, it was surmised that 1-hour CA under moderate hypothermia $\left(26^{\circ} \mathrm{C}\right)$ might be associated with much neuronal damage and high CSF Tau protein levels if no adequate perfusion adjunct is used. The results of the CSF Tau protein levels were correlated with the pathologic changes. In our study, pathologic examination revealed more severe neurologic damage in the CA group compared with that in either of the other 2 groups, especially in the hippocampus and cortex regions. Because the 1-hour CA was induced under moderate hypothermia, ischemic injury of the brain might have occurred; the brain is vulnerable at this temperature and the safe time limit for CA under these circumstances is considered to be less than 15 to 20 minutes. Although some authors insist that RCP offers little advantage even if CA is induced under deep hypothermia $\left(15^{\circ} \mathrm{C}-18^{\circ} \mathrm{C}\right)$, many dogs in the int-RCP group in our study showed good recovery 


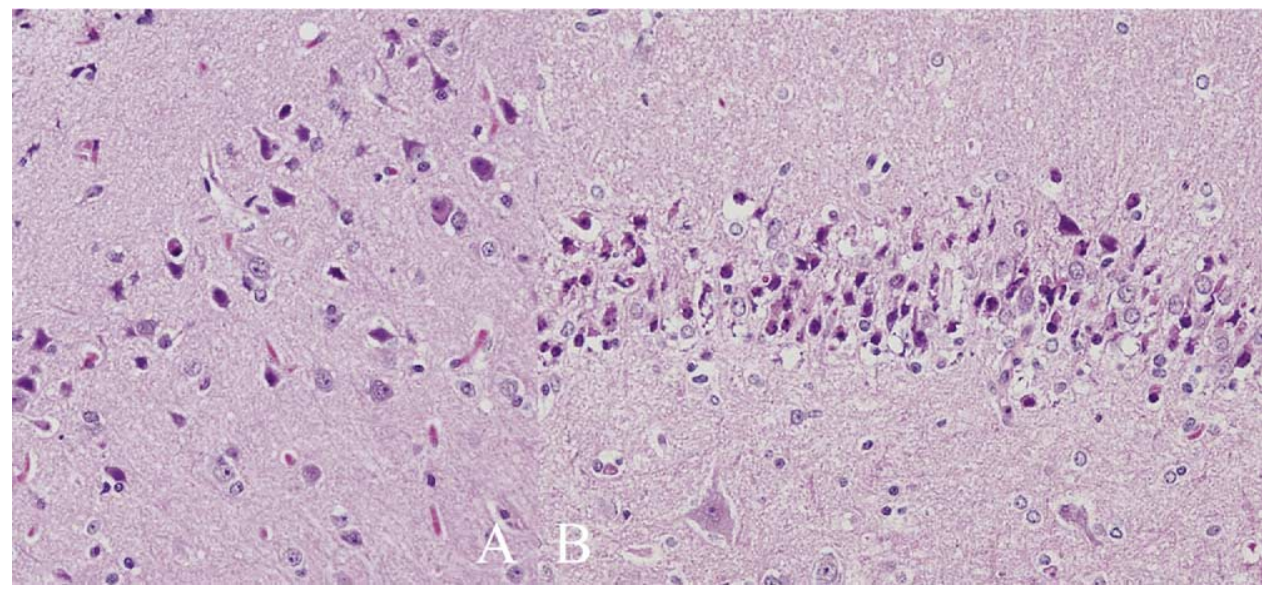

Figure 6. Histopathologic changes in the hippocampus region of the CA group. A, Degeneration of neurons.

from CA under moderate hypothermia and less severe neurologic damage than the other groups. Nevertheless, the neuroprotective effect of int-RCP under deep hypothermia, usually used for aortic operations, should be evaluated before extrapolation of these results to clinical situations.

One of the important limitations of this study arises from the anatomic differences between human and canine bodies. Because a dog has small jugular veins with many valves, oxygenated blood was perfused directly into the maxillary veins of either side to avoid the venous valves that would interfere with retrograde perfusion. ${ }^{17}$ In fact, direct visualization of the retinal vessels supported the success of RCP in our study.

In conclusion, c-RCP was not always effective at providing adequate blood flow to the brain retrogradely, resulting in poor brain protection in many animals of the c-RCP and CA groups. On the other hand, int-RCP effectively filled up the retinal microvessels and was associated with less brain damage than that in the other groups, because intermittent high pressure effectively overcame the maldistribution associated with RCP. This novel method may provide effective neurologic protection during aortic surgeries.

\section{References}

1. Newburger JW, Jonas RA, Wernovsky G, Wypij D, Hickey PR, Kuban $\mathrm{KC}$, et al. A comparison of the perioperative neurological effects of hypothermic circulatory arrest versus low flow cardiopulmonary bypass in infant heart surgery. $N$ Engl J Med. 1993;329:1057-64.

2. Svensson L, Crawford E, Hess K, Coselli J, Raskin S, Shenaq S, et al. Deep hypothermia with circulatory arrest. Determinants of stroke and early mortality in 656 patients. $J$ Thorac Cardiovasc Surg. 1993;106: 19-31.

3. Ergin M, Galla J, Lansman S, Quintana C, Bodian C, Griepp R. Hypothermic circulatory arrest in operations on the thoracic aorta: determinants of operative mortality and neurologic outcome. J Thorac Cardiovasc Surg. 1994;107:788-99.

4. Ueda Y, Miki S, Kusuhara K, Okita Y, Tahata T, Yamanaka K, et al. Surgical treatment of aneurysm or dissection involving the ascending aorta and aortic arch, utilizing circulatory arrest and retrograde cerebral perfusion. J Cardiovasc Surg. 1990;31:553-8.

5. Takamoto S, Matsuda T, Harada M, Shimamura Y, Miyata S. Simple hypothermic retrograde cerebral perfusion during aortic arch surgery. J Cardiovasc Surg. 1992;33:560-7.

6. Mills NL, Ochsner JL. Massive air embolism during cardiopulmonary bypass: causes, prevention and management. $J$ Thorac Cardiovasc Surg. 1980;80:708-17.

7. Safi H, Letsou G, Iliopoulos D, Subramaniam M, Miller CC III, Hassoun $\mathrm{H}$, et al. Impact of retrograde cerebral perfusion on ascending aortic and arch aneurysm repair. Ann Thorac Surg. 1997;63:1601-7.

8. Coselli JS. Retrograde cerebral perfusion is an effective means of neural support during deep hypothermic circulatory arrest. Ann Thorac Surg. 1997;64:908-12.

9. Bavaria JE, Woo YJ, Hall RA, Wahl PM, Acker MA, Gardner TJ. Circulatory management with retrograde cerebral perfusion for acute type A aortic dissection. Circulation. 1996;(suppl II)94:II-173-6.

10. Dong P, Guan Y, Yang J, He M, Wan C. Fundus microvascular flow monitoring during retrograde cerebral perfusion: an experimental study. Ann Thorac Surg. 2000;70:1478-82.

11. Okita Y, Takamoto S, Ando M, Morota T, Yamaki F, Kawashima Y, et al. Mortality and cerebral outcome in patients who underwent aortic arch operations using deep hypothermic circulatory arrest with retrograde cerebral perfusion: no relation of early death, stroke and delirium to the duration of circulatory arrest. J Thorac Cardiovasc Surg. 1998;115:129-38.

12. Bonser R, Wong C, Harrington D, Pagano D, Wilkes M, CluttonBrock T, et al. Failure of retrograde cerebral perfusion to attenuate metabolic changes associated with hypothermic circulatory arrest. J Thorac Cardiovasc Surg. 2002;123:943-50.

13. Boeckxstaens CJ, Flameng WJ. Retrograde cerebral perfusion does not perfuse the brain in nonhuman primates. Ann Thorac Surg. 1995;60: 319-27.

14. Ehrlich MP, Hagl C, McCullough JN, Zhang N, Shiang H, Bodian C, et al. Retrograde cerebral perfusion provides negligible flow through brain capillaries in the pig. J Thorac Cardiovasc Surg. 2001;122: 331-8.

15. Ye J, Ryner LN, Kozlowski P, Yang L, Del Bigio MR, Sun J, et al. Retrograde cerebral perfusion results in flow distribution abnormalities and neuronal damage. A magnetic resonance imaging and 
histopathological study in pigs. Circulation. 1998;98(suppl II):II-313-8.

16. Usui A, Oohara K, Tong-lin L, Murase M, Tanaka M, Takeuchi E, et al. Determination of optimum retrograde cerebral perfusion conditions. J Thorac Cardiovasc Surg. 1994;107:300-8.

17. Li Z, Yang L, Jackson M, Summers R, Donnelly M, Deslauriers R, et al. Increased pressure during retrograde cerebral perfusion in an acute porcine model improves brain tissue perfusion without increase in tissue edema. Ann Thorac Surg. 2002;73:1514-21.

18. Estrera AL, Garami A, Miller CC 3rd, Sheinbaum R, Huynh TT, Porat EE, et al. Determination of cerebral blood flow dynamics during retrograde cerebral perfusion using power M-mode transcranial Doppler. Ann Thorac Surg. 2003;76:704-10.
19. Juvonen T, Zhang N, Wolfe D, Weisz DJ, Bodian CA, Shiang HH, et al. Retrograde cerebral perfusion enhances cerebral protection during prolonged hypothermic circulatory arrest: a study in a chronic porcine model. Ann Thorac Surg. 1998;66:38-50.

20. Ono T, Okita Y, Ando M, Kitamura S. Retrograde cerebral perfusion in human brains. Lancet. 2000;356:1323.

21. Bitsch A, Horn C, Kemmling Y, Seipelt M, Hellenbrand U, Stiefel M, et al. Serum tau protein level as a marker of axonal damage in acute ischemic strike. Eur Neurol. 2002;47:45-51.

22. Zemlan F, Rosenberg W, Luebbe P, Campbell TA, Dean GE, Weiner NE, et al. Quantification of axonal damage in traumatic brain injury: affinity purification and characterization of cerebrospinal fluid tau proteins. J Neurochem. 1999;72:741-50. 